\title{
Mass Spectrometric Immunoassay for the qualitative and quantitative analysis of the cytokine Macrophage Migration Inhibitory Factor (MIF)
}

Nisha D Sherma', Chad R Borges ${ }^{1,2}$, Olgica Trenchevska', Jason W Jarvis ${ }^{1}$, Douglas S Rehder ${ }^{1}$, Paul E Oran ${ }^{1}$, Randall W Nelson ${ }^{1}$ and Dobrin Nedelkov ${ }^{1 *}$

\begin{abstract}
Background: The cytokine MIF (Macrophage Migration Inhibitory Factor) has diverse physiological roles and is present at elevated concentrations in numerous disease states. However, its molecular heterogeneity has not been previously investigated in biological samples. Mass Spectrometric Immunoassay (MSIA) may help elucidate MIF post-translational modifications existing in vivo and provide additional clarity regarding its relationship to diverse pathologies.

Results: In this work, we have developed and validated a fully quantitative MSIA assay for MIF, and used it in the discovery and quantification of different proteoforms of MIF in serum samples, including cysteinylated and glycated MIF. The MSIA assay had a linear range of $1.56-50 \mathrm{ng} / \mathrm{mL}$, and exhibited good precision, linearity, and recovery characteristics. The new assay was applied to a small cohort of human serum samples, and benchmarked against an MIF ELISA assay.
\end{abstract}

Conclusions: The quantitative MIF MSIA assay provides a sensitive, precise and high throughput method to delineate and quantify MIF proteoforms in biological samples.

Keywords: Proteomics, MALDI-TOF, Biomarker discovery, Immunoassay, Quantification, Post-translational modifications, MIF

\section{Background}

MIF (Macrophage migration inhibitory factor) is a widely expressed $12.3 \mathrm{kDa}$ cytokine with diverse physiological activities. It was first discovered in 1966 by Bloom and Bennett [1] as a component of an exudate that demonstrated the ability to inhibit random movement of macrophages in vitro. It was successfully cloned by Weiser et al. [2], revealing the approximate molecular weight of MIF, and facilitating preliminary investigations of its physiological activities. More recently it has been determined that MIF activities are mediated through extracellular receptor CD74 [3], with activation of the intracellular signaling cascade facilitated by CD44 [4]. MIF also functionally

\footnotetext{
* Correspondence: dobrin.nedelkov@asu.edu

'The Biodesign Institute at Arizona State University, Tempe, AZ 85287, USA Full list of author information is available at the end of the article
}

binds with chemokine receptors CXCR2 and CXCR4 [5], and the intracellular protein Jab1 [6]. Unlike most other cytokines, which are synthesized in a de novo manner, MIF is expressed constitutively and stored intracellularly [7].

In recent years our knowledge of MIF function has expanded to encompass diverse physiologic functions, including immune $[7,8]$, neuroendocrine $[9,10]$, and enzymatic [11-13] activities. Of note, MIF possesses several catalytic properties, including thiol protein oxidoreductase [12] and tautomerase activities $[11,13]$.

In vitro, murine, and clinical studies have indicated that MIF is a key regulator of both adaptive and innate immune functions, and also modulates the inflammatory response $[7,8]$. MIF stimulates the release of other proinflammatory molecules via an autocrine mechanism 
[14], and acts in concert with corticosteroids to regulate the inflammatory response [15]. In humans, increased circulating concentrations of MIF have been reported in inflammatory conditions such as sepsis [16,17] and rheumatoid arthritis [18]. MIF has demonstrated potential to serve as a prognostic marker in critically ill sepsis patients [19], and as a marker of pulmonary function following cardiopulmonary bypass [20].

A number of in vitro, in vivo, and clinical studies have indicated a potential involvement of MIF in the development of cardiovascular and metabolic disorders [21-28]. It has been found that MIF might be involved in the early stages of plaque development [22], and that it can promote destabilization of atherosclerotic plaques [26,28]. In mouse models, it can promote intimal thickening [23,27] and induce cardiac dysfunction [24], although one study [29] found that MIF may exert cardioprotective effects in the context of ischemic injury. Numerous clinical studies have reported elevated circulating levels of MIF in the context of cardiovascular and metabolic pathologies, including acute myocardial infarction [21,30], chronic kidney disease [31], and type 2 diabetes [32-34].

Studies of MIF function and expression in cancer have revealed a largely pro-tumorogenic role. MIF inhibits the action of tumor suppressor p53 [35], and has been implicated in the development and progression of breast [36] and lung cancer [37,38]. MIF has also been noted to circulate at elevated levels in a number of cancer subtypes, including ovarian [39], colorectal [40], breast [36], and prostate cancer [41].

While immunoassays such as ELISA and RIA are commonly used for measuring circulating protein concentrations, mass spectrometry-based approaches are becoming increasingly relevant to the clinical setting for diagnostic applications [42-44]. Recently, Campa et al. developed a mass spectrometry-based platform for MIF and cyclophilin A to quantify these proteins in non-small cell lung cancer (NSCLC) [45].

In recent years, proteomic and mass spectrometry techniques have furthered the discovery and comprehension of protein post-translational modifications (PTMs), which may have unique physiologic activities, and can be associated with or be by products of disease processes $[46,47]$. As such, PTMs may potentially serve as clinically useful markers for diagnosis, prognoses, or therapy monitoring. Accordingly, it is imperative to develop analytical techniques that can not only quantify total protein levels in biological samples, but also have the ability to discriminate between different isoforms of the target protein.

Several in vitro studies have demonstrated unique biological activities of MIF post-translational modifications. It was recently discovered that MIF is the main target of PEITC (phenethyl isothiocyanate) which binds intracellular
MIF at the $N$-terminus, diminishing MIF tautomerase enzyme activity [48]. Additionally Watarai et al. [49] demonstrated in vitro cysteinylated MIF (described by its synonym GIF) to possess elevated physiologic activity and specific immunosuppressive activities not observed for unmodified MIF, and determined the site of this modification.

While in vitro investigations have provided valuable insights into the activities of post translationally modified forms of MIF, studies of the heterogeneity of MIF in biological samples have not been previously performed. While total concentration of circulating MIF can be efficiently analyzed by ELISA assays, distinct forms of MIF cannot be differentiated. As such, a technique that can provide qualitative and quantitative analyses of MIF levels in biological matrices could facilitate the discovery of previously undetected MIF proteoforms, and may further our comprehension of the relationship of MIF with diverse pathologies.

Mass Spectrometric Immunoassay (MSIA), an immunoenrichment technique that was developed by Nelson et al. [50], utilizes antibodies immobilized to an activated solid support within an affinity pipette tip to capture the target protein species from a biological sample, which is then followed by elution and mass spectrometric analysis. Quantitative MSIA analyses can be performed wherein an internal reference standard is introduced into the biological sample and co-captured with the target protein in parallel to generate a standard curve. A number of MSIA assays have been developed for either single or multiple target proteins, with the ability to provide simultaneous qualitative and quantitative analyses within a single assay [51-53]. Here we describe the development, validation, and application of a qualitative and quantitative MSIA assay for Macrophage Migration Inhibitory Factor (MIF). The assay can both quantify and discern the molecular heterogeneity of this multifunctional cytokine.

\section{Results}

\section{Assay development}

Pooled human plasma from healthy donors was used for the initial assay development. It was determined experimentally that an addition of detergent buffer provided optimal MIF signal-to-noise ratio, with minimal presence of non-specifically bound proteins in the mass spectra. The detergent buffer had been developed for prior MSIA analyses [54,55].

Important to the development of the quantitative assay is the selection of an internal reference standard (IRS) that can simultaneously be retrieved from the sample along with the native protein and produces a consistent signal in the mass spectrum that is distinct from any naturally occurring isoforms of the target protein. We selected $C$-terminally labeled His tag MIF which has a 
mass of 13,411 Da. By selecting an internal reference standard that is in the same $\mathrm{m} / \mathrm{z}$ range as human MIF, but adequately shifted from human MIF in a spectrum region free of peaks, potential overlap with endogenous forms of human MIF is averted.

Shown in Figure 1 is a representative mass spectrum from the MIF MSIA performed on a serum sample to which $10 \mathrm{ng} / \mathrm{mL}$ His tag MIF has been added as an internal reference standard (IRS). Peaks in the mass spectrum correspond to endogenous forms of MIF, including native (intact) $\mathrm{MIF}\left(\mathrm{m} / \mathrm{z}_{\mathrm{obs}}=12346.1\right)$, cysteinylated $\operatorname{MIF}\left(\mathrm{m} / \mathrm{z}_{\mathrm{obs}}=12465.0, \mathrm{~m} / \mathrm{z}_{\mathrm{calc}}=12465.3\right)$ and glycated $\operatorname{MIF}\left(\mathrm{m} / \mathrm{z}_{\text {obs }}=12509.6, \mathrm{~m} / \mathrm{z}_{\text {calc }}=12508.3\right)$. Also present are peaks of the sinapic acid matrix adduct $\left(\mathrm{m} / \mathrm{z}_{\mathrm{obs}}=\right.$ $\left.12551.9, \mathrm{~m} / \mathrm{z}_{\text {calc }}=12552.2\right)$ and His tag $\operatorname{MIF}\left(\mathrm{m} / \mathrm{z}_{\mathrm{obs}}=\right.$ 13411.1, $\mathrm{m} / \mathrm{z}_{\mathrm{calc}}=13411.2$ ).

Also important to assay development is the selection of a suitable matrix in which to perform standard curve dilutions. We considered animal plasma due to similarity in properties to human plasma. However, this was not feasible, due to the cross reactivity of the MIF antibody with endogenous goat, bovine, and equine MIF. As such, we utilized $10 \mathrm{mg} / \mathrm{mL}$ of Human Serum Albumin in $\mathrm{PBS}$, a solution roughly iso-tonic and iso-osmotic to human plasma/serum.

\section{Assay validation}

Recent years have brought about rapid advances in bioanalytical methodologies, and an increase in the routine research [47] and clinical use of mass spectrometers [42,43] for quantitative analyses. As such, there is a growing interest in streamlining pre-study validation measures to ensure reliable assay performance [56-59]. The performance characteristics that were evaluated for the MIF MSIA assay included intra-assay (within run) and inter-assay (between runs) precision, spiking recovery, and dilution linearity.

To analyze the intra-assay and inter-assay precision, a 3-day experiment was performed in which 3 replicates of a single serum sample were analyzed per day by MSIA. A standard curve was run with each analysis. A representative standard curve, along with the MIF standards mass spectra, is shown in Figure 2. A linear dynamic range was observed with the standard curve, with an average R-squared for all three days of 0.99 . The intra-day CV values were $3.97 \%, 8.42 \%$, and $3.14 \%$ respectively, and the inter-day CV was $8.21 \%$ (Table 1 ).

To analyze the dilution linearity of endogenous MIF, two experiments involving serial two-fold dilutions were performed with serum samples with a known intact MIF concentration, on two separate days. The serum sample was diluted $2 \times, 4 \times$, and $8 \times$ in a $10 \mathrm{ng} / \mathrm{mL}$ solution of HSA in PBS. The concentrations were calculated via the accompanying standard curve. The percent recovery was determined by dividing the observed by the expected concentrations (Table 2).

To analyze the spiking recovery, two experiments were performed, on two separate days, in which a serum sample containing a low endogenous concentration of MIF

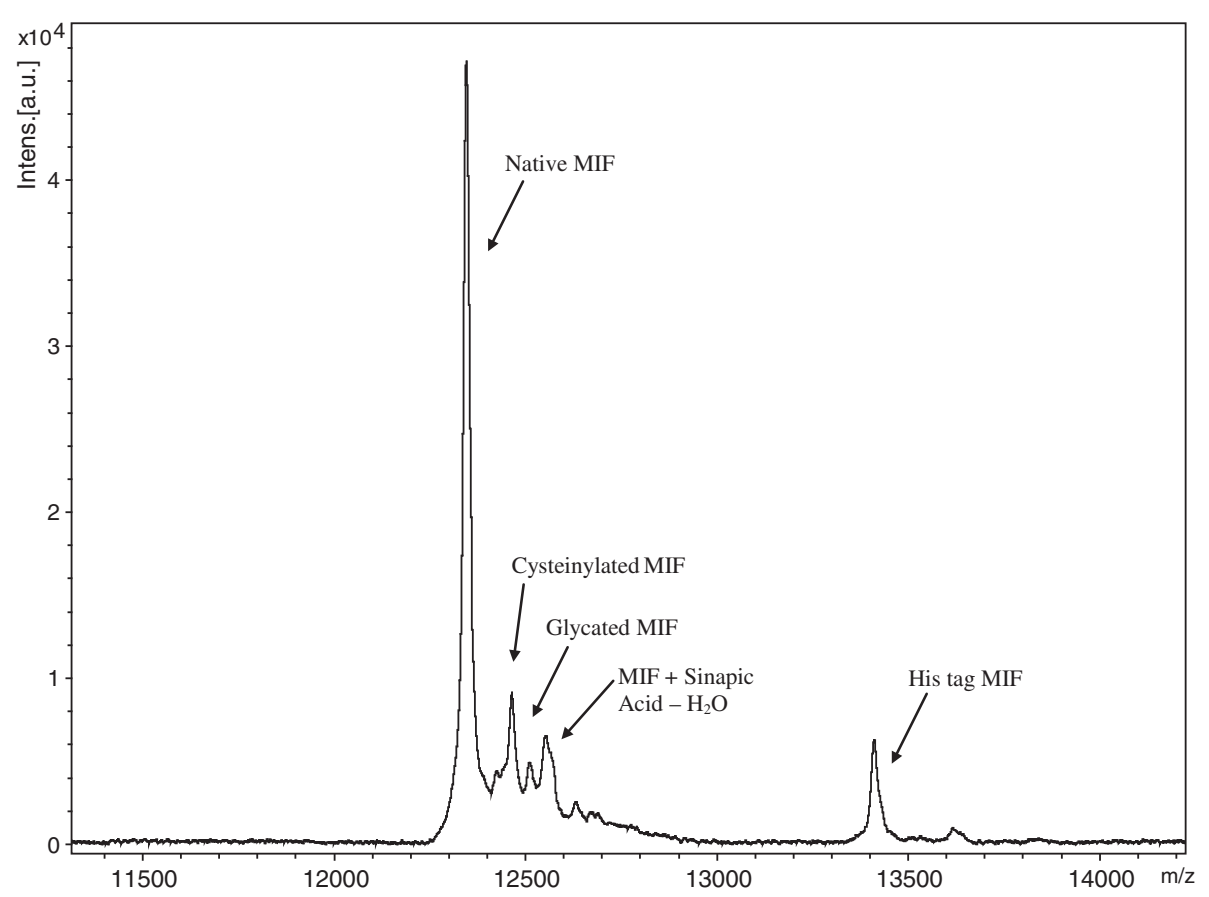

Figure 1 Representative MIF Spectra from MSIA performed on healthy male serum sample with peaks corresponding to native (intact) MIF, cysteinylated MIF, glycated MIF, sinapic acid matrix adduct, and His tag MIF. 
a

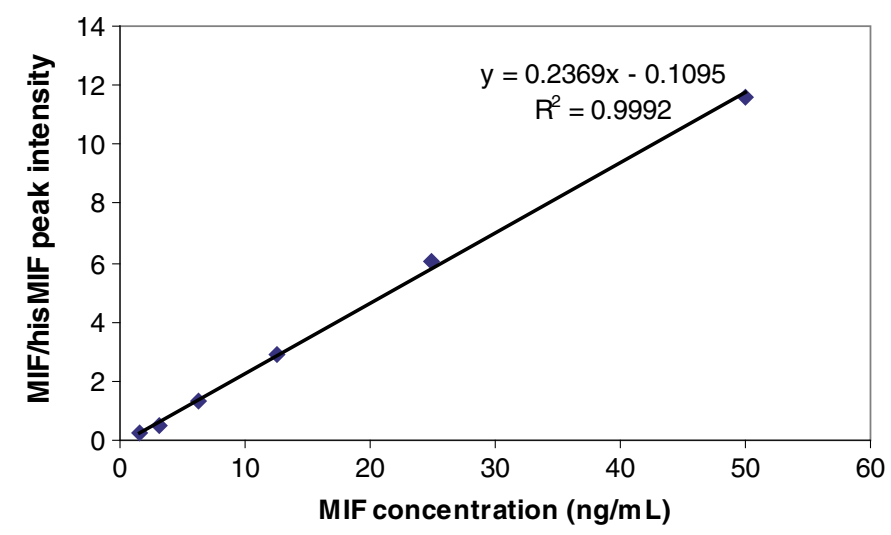

b

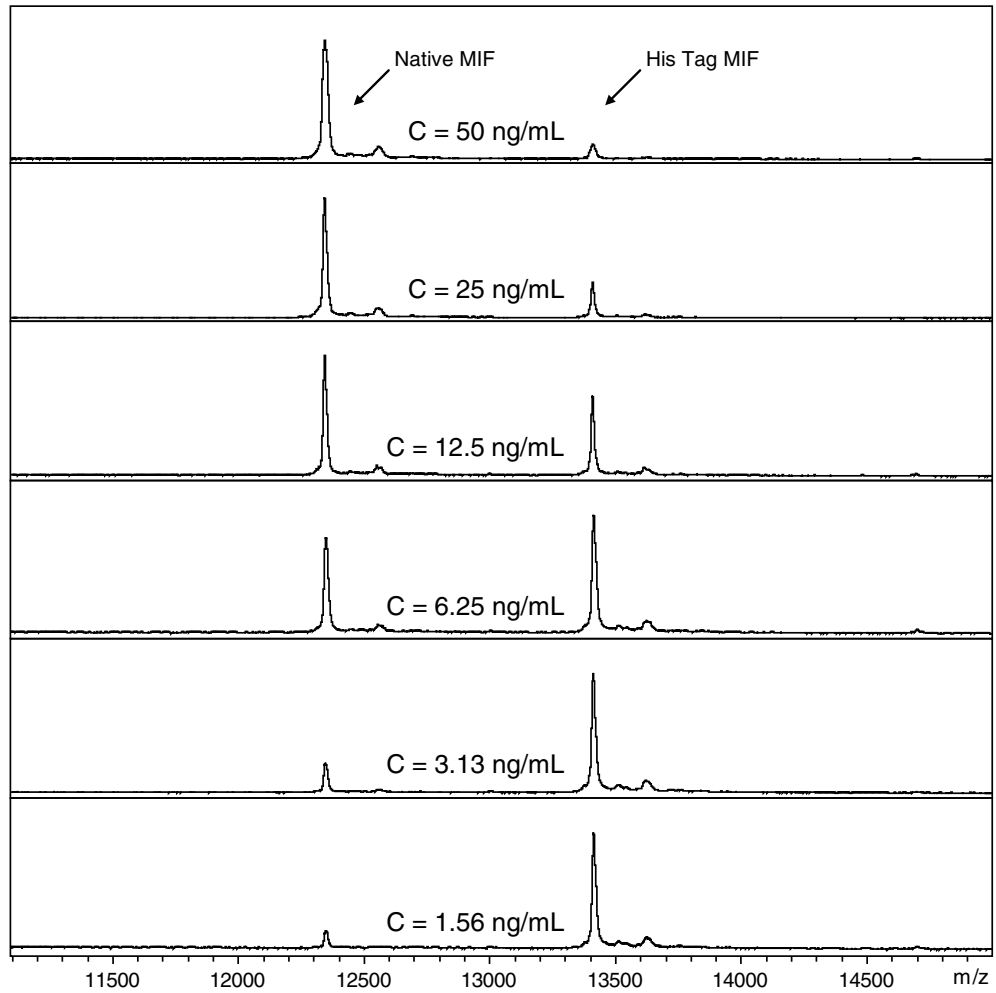

Figure 2 Representative standard curve for MIF MSIA with linear range of $1.56-\mathbf{5 0} \mathbf{n g} / \mathbf{m L}$. a) MIF-to-His tag MIF ratios are plotted against concentrations of standards to create the plot; $\mathbf{b})$ Representative MALDI TOF mass spectra from the MIF and His tag MIF standards used to generate the standard curve.

Table 1 Intra- and inter-assay precision

\begin{tabular}{lllllll}
\hline Intra-assay CVs & & & & & \multicolumn{2}{l}{ Inter-assay CV } \\
\cline { 1 - 4 } \cline { 1 - 2 } Day: & $\mathbf{1}$ & $\mathbf{2}$ & $\mathbf{3}$ & & \\
\hline STDEVP: & 1.23 & 3.01 & 1.18 & & STDEVP & 2.85 \\
MEAN (ng/mL): & 30.9 & 35.7 & 37.7 & & MEAN & 34.8 \\
CV (\%): & 3.97 & 8.42 & 3.14 & & CV & 8.21 \\
\hline
\end{tabular}

3 replicates of a serum sample were analyzed per day on 3 consecutive days. was fortified with recombinant MIF. For each experiment, four $200 \mu \mathrm{L}$ aliquots of the serum sample were supplemented with $20,10,5$, and $0 \mathrm{ng} / \mathrm{mL}$ of recombinant MIF protein respectively, via addition of $100 \mu \mathrm{L}$ of $40 \mathrm{ng} / \mathrm{mL}, 20 \mathrm{ng} / \mathrm{mL}, 10 \mathrm{ng} / \mathrm{mL}$, and $0 \mathrm{ng} / \mathrm{mL}$ of recombinant MIF protein (prepared in PBS-HSA buffer). A $100 \mu \mathrm{L}$ aliquot of IRS (40 ng/mL His tag MIF in PBSHSA buffer), and a $100 \mu \mathrm{L}$ aliquot of detergent buffer were then added to the samples and standards, and MSIA was performed. The MIF concentrations were 
Table 2 Assay linearity

\begin{tabular}{lllll}
\hline Sample & Dilution & $\begin{array}{l}\text { Observed } \\
\mathbf{n g} / \mathbf{m L}\end{array}$ & $\begin{array}{l}\text { Expected } \\
\mathbf{n g} / \mathbf{m L}\end{array}$ & $\begin{array}{l}\text { Recovery } \\
\text { O/E \% }\end{array}$ \\
\hline $\mathbf{1}$ & & 31.5 & & \\
& $2 \times$ & 15.5 & 15.7 & 98.3 \\
& $4 \times$ & 7.36 & 7.87 & 93.5 \\
& $8 \times$ & 4.20 & 3.93 & 107 \\
$\mathbf{2}$ & & 29.2 & & \\
& $2 \times$ & 13.6 & 14.6 & 93.2 \\
& $4 \times$ & 7.00 & 7.30 & 95.9 \\
& $8 \times$ & 4.20 & 3.65 & 115 \\
\hline
\end{tabular}

Serum samples were, on two separate days, serially diluted $2 \times, 4 \times$ and $8 \times$ and MSIA was performed. Intact MIF concentrations were determined from accompanying standard curve.

calculated from the accompanying standard curve equation. The percent recovery of MIF in each sample was determined from the ratio of observed to expected concentrations (Table 3).

\section{Method comparison - MSIA and ELISA analyses of MIF concentrations in healthy serum samples}

The optimized and validated MSIA MIF assay was used to analyze serum samples obtained from 22 healthy males ranging in age from 46 to 73 . The serum samples were analyzed by quantitative MSIA in parallel with an accompanying standard curve, as described in the previous section. The standard curve exhibited good linearity, with an R-squared value of 0.99 . A peak corresponding to glycated MIF was observed in 21 of the 22 samples, and a peak corresponding to cysteinylated MIF was observed in 18 of the 22 samples. The total MIF concentrations (sum of all MIF isoform concentrations) ranged from 11.9 to $92.7 \mathrm{ng} / \mathrm{mL}$, with a mean of $36.2 \mathrm{ng} / \mathrm{mL}$. Cysteinylated MIF concentrations ranged from 1.82 to $5.44 \mathrm{ng} / \mathrm{mL}$ and glycated MIF concentrations ranged from 1.82 to $17.40 \mathrm{ng} / \mathrm{mL}$.

Table 3 Spiking recovery

\begin{tabular}{lllll}
\hline Sample & $\begin{array}{l}\text { MIF added } \\
\mathbf{n g} / \mathbf{m L}\end{array}$ & $\begin{array}{l}\text { Observed } \\
\mathbf{n g} / \mathbf{m L}\end{array}$ & $\begin{array}{l}\text { Expected } \\
\mathbf{n g} / \mathbf{m L}\end{array}$ & $\begin{array}{l}\text { Recovery } \\
\text { O/E\% }\end{array}$ \\
\hline $\mathbf{1}$ & 0 & 12.5 & & \\
& 5 & 16.3 & 17.5 & 93.1 \\
& 10 & 20.9 & 22.5 & 92.9 \\
& 20 & 31.5 & 32.5 & 96.9 \\
$\mathbf{2}$ & 0 & 15.4 & & \\
& 5 & 21.9 & 20.4 & 108 \\
& 10 & 24.8 & 25.4 & 97.7 \\
& 20 & 35.1 & 35.4 & 99.2 \\
\hline
\end{tabular}

A serum sample was fortified with $0 \mathrm{ng} / \mathrm{mL}, 5 \mathrm{ng} / \mathrm{mL}, 10 \mathrm{ng} / \mathrm{mL}$, and $20 \mathrm{ng} / \mathrm{mL}$ recombinant MIF protein and MSIA was performed. Intact MIF concentrations were determined from accompanying standard curve.
ELISA for the 22 serum samples was performed with Quantikine ELISA kit (R\&D systems), but using Fitzgerald MIF protein in place of R\&D Systems MIF standard. The samples were run in duplicate and the concentrations were averaged. The assay was performed according to the manufacturer instructions, on a Thermo Scientific Multiskan GO spectrophotometer. The MIF concentrations ranged from 11.7 to $91.7 \mathrm{ng} / \mathrm{mL}$, with a mean of $42.8 \mathrm{ng} / \mathrm{mL}$.

A good correlation was observed between ELISA MIF and MSIA total MIF concentrations, with a negative 17.7 percent bias, as revealed by the Altman-Bland [60,61] plot (Figure 3), which shows (a) a Scatter plot and (b) a Difference plot. A Passing Bablok [62] regression equation of $y=-2.76+0.89 \times$ was obtained, with a Cusum linearity $\mathrm{p}$ value of 0.78 .

\section{Stability analyses of MIF protein standard}

Changes in protein stability as a result of variations in sample storage and handling may introduce unanticipated analytical variability [63]. As such, efforts must be undertaken to experimentally identify potential sources of variability that may affect the analysis, and to establish the optimal storage and handling conditions for the samples and protein standards. Accordingly, we performed experiments to assess the stability of the $1 \mathrm{mg} /$ $\mathrm{mL}$ recombinant MIF protein under the following conditions: storage undiluted at $-80^{\circ} \mathrm{C}$, storage diluted in $40 \mathrm{ng} / \mathrm{mL}$ PBS-HSA buffer at $-80^{\circ} \mathrm{C}$, and prolonged storage undiluted at $4^{\circ} \mathrm{C}$.

To evaluate the stability of the $1 \mathrm{mg} / \mathrm{mL}$ Fitzgerald MIF protein when it is stored at $-80^{\circ} \mathrm{C}$ but thawed and re-frozen after each use, we performed a three-day experiment in which a tube of $1 \mathrm{mg} / \mathrm{mL}$ recombinant MIF protein was stored at $-80^{\circ} \mathrm{C}$. On each of three days, the tube was thawed and an aliquot was removed and used to fortify a plasma sample with $20 \mathrm{ng} / \mathrm{mL}$ MIF. The tube was then placed back at $-80^{\circ} \mathrm{C}$. Plasma from the same individual was used on each day. Pre-aliquoted His tag MIF was added fresh on each day into the spiked plasma sample at $10 \mathrm{ng} / \mathrm{mL}$ prior to MSIA analysis. The ratio of MIF/HisMIF peak intensities decreased on each subsequent day, from 24.56 to 20.45 to 13.71 , an average dayto-day decrease of $24.85 \%$.

To determine whether the MIF protein is stable in terms of its immunoreactivity toward anti-MIF antibody when stored frozen in a solution of albumin in PBS buffer, we performed an experiment in which $1 \mathrm{mg} / \mathrm{mL}$ recombinant MIF protein was diluted to $0.1 \mathrm{mg} / \mathrm{mL}$ in $40 \mathrm{ng} / \mathrm{ml}$ PBS-HSA buffer and stored at $-80^{\circ} \mathrm{C}$. On each of 3 days, the $10 \times$ diluted MIF protein was taken out and used to fortify a plasma sample to $20 \mathrm{ng} / \mathrm{mL}$. Pre-aliquoted His tag MIF was added fresh on each day into the sample at $10 \mathrm{ng} / \mathrm{mL}$ immediately prior to MSIA analysis. The MIF/ 

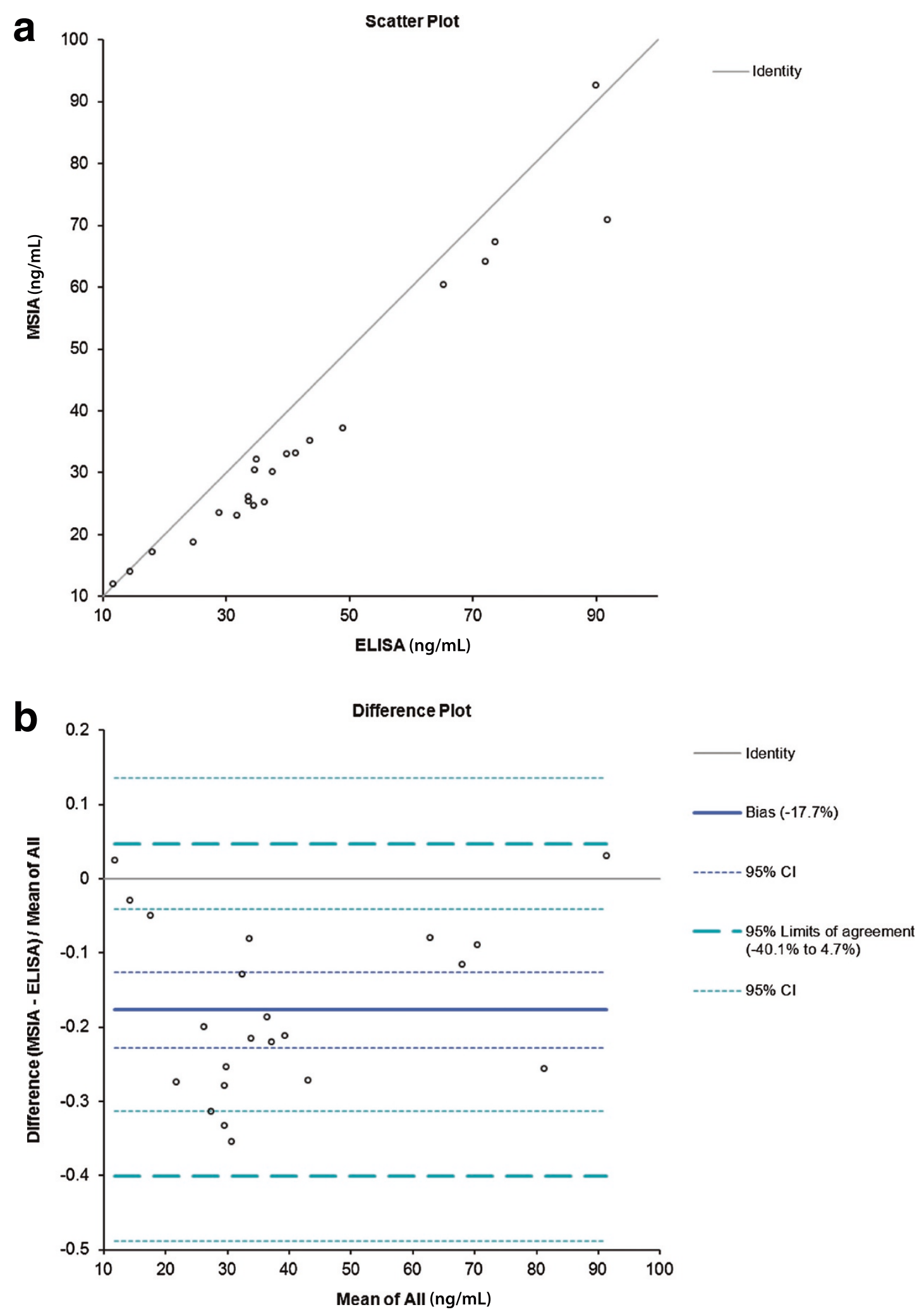

Figure 3 Histogram of MIF concentrations determined by MSIA and ELISA for 22 healthy male serum samples. a) Scatter plot showing the direct comparison between the MIF concentrations obtained with developed MSIA and reference ELISA method; $\mathbf{b})$ Altman-Bland difference plot reveals slight negative correlation (bias $=-17.7 \%$ ) between the MIF concentrations obtained by MSIA vs the reference ELISA method. 
HisMIF peak intensity ratios of $15.27,15.87$, and 15.20 were relatively consistent from days one through three (an average variation of $4.11 \%$ per day), indicating that the MIF protein was stable when stored frozen at $-80^{\circ} \mathrm{C}$.

To analyze the stability of MIF protein when stored at $4^{\circ} \mathrm{C}$, we performed an experiment in which recombinant MIF protein from a freshly received vial at $1 \mathrm{mg} / \mathrm{mL}$ concentration was stored at $4{ }^{\circ} \mathrm{C}$ and used to fortify a plasma sample with $20 \mathrm{ng} / \mathrm{mL}$ of MIF. The experiment was repeated after 6 and 12 days. Pre-aliquoted His tag MIF at $10 \mathrm{ng} / \mathrm{mL}$ was added fresh on each day just prior to MSIA analysis. The MIF/HisMIF peak intensity ratios were evaluated and remained relatively unchanged after both 6-day and 12-day intervals. The ratios were 15.72 , 15.10 , and 15.61 on days 0,6 , and 12 , an average variation of $3.66 \%$ per day. As such, we concluded that the recombinant MIF protein is stable for at least 12 days stored at $4^{\circ} \mathrm{C}$, and employed this sample storage for the analyses.

\section{Quantitative comparison of MIF in different specimen collection types}

Anti-coagulants such as EDTA, heparin, and citrate are often added to plasma collection tubes, inhibiting coagulation via unique mechanisms [64]. However, differences in plasma collection tube additives may produce sample characteristics that result in differences in measurable protein concentrations, and this may introduce analytical bias into a quantitative biomarker investigation when not accounted for [63]. Hence, it is important to determine how differences in sample collection tubes may affect the analysis, and to determine the optimal specimen type for the analysis.

With this in mind, we performed a quantitative MIF MSIA analysis in order to compare the differences in measurable MIF concentrations among different sample collection types. We analyzed matched sets obtained from Bioreclamation, of 5 samples each, from 6 donors (30 samples total). Each set of 5 samples consisted of one serum sample and four plasma samples: $3.8 \% \mathrm{NaCi}$ trate plasma, $K_{2}$ EDTA plasma, $K_{3}$ EDTA plasma, and $\mathrm{Na}_{2}$ EDTA plasma.

Total MIF concentrations were higher in serum than any of the plasma types, and lowest in $\mathrm{Na}_{2}$ EDTA plasma and 3.8\% NaCitrate plasma. Box Plots of total MIF concentrations comparing different sample collection types are shown in Figure 4. Friedman's test with multiple pairwise comparisons was carried out to look for significant differences between sample types. Significant differences, indicated by $\mathrm{p}$-values of $<0.005$, were found for serum vs $3.8 \% \mathrm{NaCitrate}$ plasma, for serum vs $\mathrm{Na}_{2} \mathrm{EDTA}$ plasma, and between $3.8 \%$ NaCitrate plasma vs $K_{2}$ EDTA plasma.

\section{MIF glycation mapping}

We observed a peak corresponding to a tentative MIF glycation event in 21 of the 22 healthy male serum samples that we analysed by MSIA. To characterize this modification and potentially pinpoint its molecular location, we developed an in-solution pepsin digest method and initially applied it to in vitro glycated recombinant MIF, with the goal of applying the pepsin digestion procedure to a MSIA MIF elution of a serum sample that contains endogenous glycated MIF. MIF has 3 lysines (potential glycation sites) at positions 32,66 , and 77 Figure 5. In-solution pepsin digest was performed for both unmodified and artificially glycated MIF as described in the methods section. In-solution pepsin digest resulted in $100 \%$ sequence coverage based on mass mapping. In the digest spectra of glycated recombinant MIF, 4 unique glycated fragments were identified on the basis of mass mapping to within $0.1 \mathrm{Da}$ mass accuracy, and

Comparison of Total MIF concentrations among different sample

types

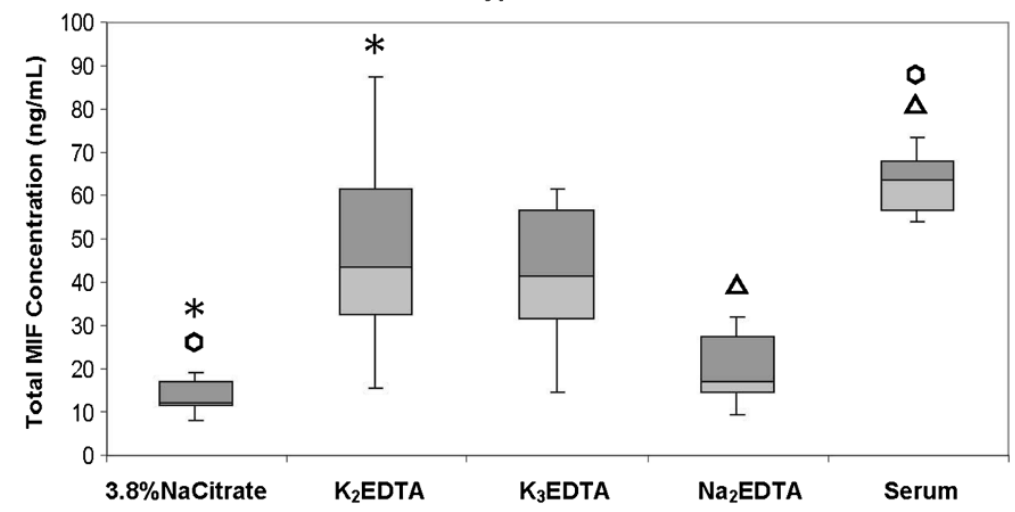

Figure 4 Comparison of total MIF concentrations among different sample collection types. Significant differences, determined by Friedman's test with multiple pairwise comparisons, are indicated by p-values of $<0.005$. Matching symbols designate significant differences. 


\section{MIF (human) [1-114] mass $=12346.1$}

$\begin{array}{clllllll}\text { Small polar: } & \mathrm{D}(4) & \mathrm{E}(3) & \mathrm{N}(8) & \mathrm{Q}(6) & & & \\ \text { Large polar: } & \mathrm{K}(3) & \mathrm{R}(5) & \mathrm{H}(2) & & & & \\ \text { Small non-polar: } & \mathrm{S}(10) & \mathrm{T}(4) & \mathrm{A}(11) & \mathrm{G}(9) & & & \\ \text { Large non-polar: } & \mathrm{L}(11) & \mathrm{I}(6) & \mathrm{V}(8) & \mathrm{M}(3) & \mathrm{F}(4) & \mathrm{Y}(5) & \mathrm{W}(1) \\ \text { Special: } & \mathrm{C}(3) & \mathrm{P}(8) & & & & & \end{array}$

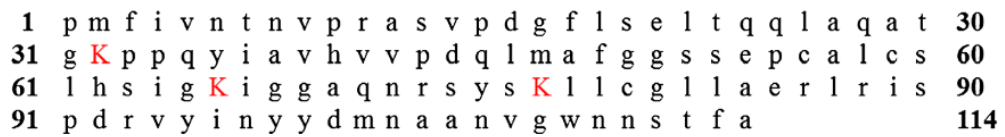

Figure 5 Sequence of intact MIF, with lysine residues highlighted.

absence in the digest spectra of unmodified MIF, including a peptide corresponding to glycated $\mathrm{I}[4-46] \mathrm{L}$, a peptide corresponding to $\mathrm{C}[59-82] \mathrm{L}$ and peptides corresponding to both single and double glycation of fragment C[59-83] $\mathrm{L}$ which has lysines at 66 and 77 . As such, it is likely that recombinant, artificially glycated MIF can be glycated at all three lysine residues. Additional studies will need to be undertaken to determine if endogenous MIF is glycated in a site-specific manner.

\section{Discussion}

The MSIA workflow enables an efficient and high-throughput analysis of up to 96 samples in parallel, using an automated robotic workflow for both antibody coupling and immunoaffinity enrichment of analytes. The ability to identify non-specifically bound proteins, as well as discern between various isoforms of the target protein, provides the specificity needed for clinical analyses, while the use of standard curve and an internal reference standard facilitates simultaneous analyte quantitation.

Our MSIA analysis of MIF has revealed unique qualitative and quantitative profiles of MIF within individual serum samples. Importantly, our work has facilitated the discovery of variants of MIF that cannot be individually discerned using conventional non-MS based immunoassay approaches. With the MSIA assay, we detected several isoforms of MIF to be present endogenously within serum samples, including cysteinylated and glycated MIF. To our knowledge, these forms of MIF have not previously been detected or quantified from biological samples.

Of clinical relevance to metabolic disorders is protein glycation, a non-enzymatic binding of glucose to proteins [65]. Recent studies involving in vitro glycation and subsequent in-solution proteolysis have enabled the elucidation of glycation sites of recombinant proteins, including HSA [66]. Given that glycation of MIF has not, to our knowledge, been described previously, we pursued further characterization of this modification, and determined that MIF glycation can occur at any of the three lysine residues.
Differences in measured concentrations between sample collection types, as we have observed for MIF, may be a result of multiple factors. Various anticoagulants differ in mechanisms [64], and certain additives may form complexes with serum/plasma proteins, decreasing immunoreactivity [67]. Such differences have been reported in various studies [67,68], Notably, Skogstrand et al. [69], in a study of inflammatory markers, concluded that higher measurable concentrations in serum compared to plasma is due to the longer storage time for serum prior to centrifugation which allows, during the coagulation process, for the gradual release of inflammatory markers that had been sequestered by blood proteins they are associated with. While discrepancies in quantitative measurements between different sample collection types are somewhat unsurprising, our results suggest that quantitative comparisons between sample cohorts should only be made amongst specimens of the same collection type.

A small negative bias of $-17.7 \%$ was observed between the MSIA and ELISA MIF analyses. The reason for the bias is not clear, but interference from non-specific interactions with the antibodies employed in the ELISA analysis could play a role, resulting in elevated ELISA measured concentrations of MIF compared to MSIA.

Biomarker assays have a long history in clinical use for determining prognoses, assessment of response to therapy, and in diagnostics $[44,59]$, and recent years have seen the emergence of diverse MS based quantitative assay methodologies. When developing a new quantitative method for biomarker analysis, assay validation is critical to ensuring a robust and reproducible method. However the criteria used to validate assays can differ, and streamlining of validation criteria is needed to ensure reliable and reproducible results. CLIA has put forth requirements for clinical labs [70], and as proteomics research has brought about novel techniques for quantitative protein analysis, interest has recently emerged in the research community with regard to harmonizing criteria for assay performance parameters. This can help enable technology transfer. Though methodologies can vary greatly, Lee et al. [59] have suggested a 
"fit-for-purpose" approach that can be applied to a wide range of analytical platforms; a set of recommended validation parameters that can be tailored to the specific needs and intended utility of the study.

In the development of our MIF quantitative MSIA assay, we have employed several of these validation measures, including intra- and inter-day precision, recovery, and dilution linearity. In addition, we have also performed assessment of protein stability, comparison with another existing assay, and comparison of different blood collection tubes. The inter-assay and intra-assay $\mathrm{CVs}$ and the assay linearity and spiking recovery experiments confirm the performance of the MIF MSIA assay.

In combining selective immunoaffinity enrichment of protein analytes with mass spectrometry, detailed molecular analysis is enabled, with the ability to both identify and quantify different proteoforms. With this added dimension of molecular heterogeneity, the MSIA assay provides the unique capability to address the molecular differences that may be present in diseased individuals relative to healthy subjects. Post translational modifications (PTMs) of a protein may impart unique physiological activities, and may be present in different proportions relative to the intact protein in the case of disease states. Accordingly, a targeted assay that examines the diversity of proteoforms in sample populations can facilitate the identification of unique disease biomarkers based on protein PTMs, potentially enabling more sensitive and specific detection of disease.

The molecular heterogeneity that we have identified is particularly interesting in light of the complex, multifaceted nature of this protein. A cross sectional MSIA study consisting of diverse diseased and non-disease patient samples may help elucidate the relationship between the abundance of intact, cysteinylated, and glycated MIF and the pathologies in which MIF may potentially play a role. As such, our assay may be valuable for researchers investigating the relationship between MIF and inflammatory disease states.

\section{Materials and methods \\ Reagents}

Anti-human MIF antibody was obtained from AbD Serotec (Raleigh, NC). Recombinant Human MIF protein was obtained from Fitzgerald (Acton, MA). Recombinant $C$-terminal His tag MIF was purchased from Cell Sciences (Canton, MA). $N$-methyl pyrrolidone (NMP) was obtained from Fisher Scientific (Waltham, MA). Phosphate buffered saline (PBS) and MES were obtained from Thermo Scientific (Waltham, MA). HBS-N buffer (0.1 M HEPES, $1.5 \mathrm{M}$ $\mathrm{NaCl}$ ) was prepared with $\mathrm{NaCl}$ and HEPES from SigmaAldrich (St. Louis, MO). CDI (carbonyldiimidazole), sinapic acid, ethanolamine, human serum albumin (HSA), $n$-octyl glucopyranoside, tween-20, ammonium acetate,
D-(+)-glucose, diethylenetriaminepentaacetic acid (DTPA), sodium azide, toluene, tris(2-carboxyethyl)phosphine (TCEP), acetonitrile, and trifluoroacetic acid were obtained from Sigma-Aldrich (St. Louis, MO).

\section{Preparation of anti-MIF MSIA affinity pipettes}

MSIA affinity pipette tips with porous microcolumns were obtained from Thermo Fisher Scientific (Tempe, AZ). Using a Beckman Multimek Automated 96-channel robot, the MSIA affinity pipette tips were CDI-activated, as described in previous protocols [71]. To the activated MSIA pipettes, anti-MIF antibody from AbD Serotec was covalently immobilized. It was empirically determined that $2.5 \mu \mathrm{g}$ of antibody diluted in MES to a volume of $30 \mu \mathrm{L}$ per well provided the optimal trade-off between antibody cost and assay performance. The antibody-derivatized MSIA tips were stored at $4{ }^{\circ} \mathrm{C}$ until later use.

\section{Preparation of standard curve and analytical samples}

We developed a 6-point standard curve to enable MIF quantification in biological samples. Prior to analysis, samples were thawed on ice, and centrifuged at 12,700 g for 5 minutes. A standard curve was performed in parallel with each sample run. For the assay standards, we used recombinant MIF protein from Fitzgerald. To perform the standard curve, the MIF recombinant protein was serially diluted in a solution of $10 \mathrm{mg} / \mathrm{mL}$ HSA in PBS. The concentrations of the MIF standards ranged from 1.56 to $50 \mathrm{ng} / \mathrm{mL}$. His tag MIF, prepared at a concentration of $20 \mathrm{ng} / \mathrm{mL}$ in $10 \mathrm{ng} / \mathrm{mL}$ HSA in PBS, was used as an internal reference standard for quantitative analysis. A $200 \mu \mathrm{L}$ aliquot of $20 \mathrm{ng} / \mathrm{mL}$ His tag MIF was added to $200 \mu \mathrm{L}$ of samples and standards. The samples tray was then incubated at room temperature on a plate shaker at 750 RPM for 2 minutes to mix the sample and internal standard. A $100 \mu \mathrm{L}$ aliquot of detergent buffer (1.5 M ammonium acetate, $0.15 \mathrm{M} \mathrm{N}$-octyl-glucopyranoside, concentrated PBS $(0.67 \mathrm{~mol} / \mathrm{L}$ sodium phosphate, $1 \mathrm{M} \mathrm{NaCl}$ ), and $4.4 \% \mathrm{v} / \mathrm{v}$ tween-20) was added to all samples and standards immediately prior to MSIA extraction.

\section{Mass spectrometric immunoassay}

Following preparation of standards and samples, immunoaffinity extraction of MIF was carried out on a Beckman Multimek 96-channel robotic workstation, with MSIA affinity pipettes derivatized with AbD Serotec anti-MIF antibody. The pipettes were first pre-rinsed via 10 aspiration and dispense cycles in a volume of $150 \mu \mathrm{L}$ PBS w/0.1\% Tween. Next, 1000 aspiration and dispense cycles in the samples ( $500 \mu \mathrm{L}$ total sample volume) were performed to allow for the flow of sample through the microcolumns and enable extraction of MIF from the 
samples. Next, the MSIA pipettes were rinsed sequentially with PBS w/0.1\% tween (75 aspiration and dispense cycles, $150 \mu \mathrm{L}$ volume), $\mathrm{H}_{2} \mathrm{O}$ (20 cycles, $150 \mu \mathrm{L}$ ), $100 \mathrm{mM}$ Tris $\mathrm{HCl}(10$ cycles, $150 \mu \mathrm{L})$ and $\mathrm{H}_{2} \mathrm{O}$ (30 cycles, $150 \mu \mathrm{L}$ ). Elution of captured protein onto the MALDI target was achieved via aspiration of $6 \mu \mathrm{L}$ of sinapic acid matrix (a saturated aqueous solution containing 33\% v/v acetonitrile and $0.4 \% \mathrm{v} / \mathrm{v}$ trifluoroacetic acid) followed by 28 aspirate and dispense cycles and subsequent release of the droplets onto the MALDI target. The droplets were air-dried to allow for co-crystallization of the matrix and proteins. Mass spectra were acquired on a Bruker Ultraflex MALDI-TOF mass spectrometer operating in positive-ion, delayed extraction linear mode, with ion source 1 at $25.00 \mathrm{kV}$, ion source 2 at $23.10 \mathrm{kV}$, lens at $9.00 \mathrm{kV}, 90 \mathrm{~ns}$ delay, and $1 \mathrm{GS} / \mathrm{s}$ sample rate. Approximately 5,000 laser shots were acquired for each mass spectrum and summed. Prior to acquisition of the mass spectra, the target mass range was externally calibrated using a mixture of calibrants obtained from Bruker Daltonics (Billerica, MA), consisting of insulin, ubiquitin, cytochrome $\mathrm{C}$ and myoglobin. The calibrant mix was diluted 15-fold in sinapic acid matrix and $1 \mu \mathrm{L}$ spotted onto the MALDI target. Following data collection, the mass spectra was imported into Bruker Daltonics FlexAnalysis software, smoothed (Savitzky-Golay algorithm) and baseline subtracted (Tophat algorithm). All MIF peak intensities are entered into an Excel spreadsheet. The ratio of peak intensities of MIF standards to His tag MIF was plotted against the concentrations of the MIF standards to create the standard curve. The concentrations of endogenous human MIF, including intact, cysteinylated and glycated MIF, were computed using the equation from the standard curve.

\section{Human samples}

Healthy pooled human plasma for initial assay development was purchased from PromedDx (Norton, MA). Healthy male serum samples were purchased from PromedDx (Norton, MA). The samples were de-identified and labeled with only a barcode. We utilized 22 of these samples, which ranged in age from 46 to 73 for analysis by MSIA and ELISA assays. Matched sets, consisting of 5 sample collection types for each individual were obtained from Bioreclamation (Hicksville, NY). The samples were de-identified and labeled with only a barcode. Sample types included: $3.8 \% \mathrm{NaCitrate}$ plasma, $\mathrm{K}_{2}$ EDTA plasma, $\mathrm{K}_{3}$ EDTA plasma, $\mathrm{Na}_{2}$ EDTA plasma, and serum. We analyzed 5 sample collection types from 6 individuals (30 samples total).

\section{In vitro glycation of MIF}

To perform in vitro glycation, $1 \mathrm{mg} / \mathrm{mL}$ recombinant MIF protein was incubated with $0.5 \mathrm{M}$ glucose solution in a 1:1 volume ratio. The glucose solution contained $0.2 \mathrm{M}$ sodium phosphate buffer with $1 \mathrm{mM}$ diethylenetriaminepentaacetic acid (DTPA) added to chelate trace amounts of transition metal ions (e.g. iron, copper, etc.) from the phosphate buffer which may otherwise catalyze unintended auto-oxidation reactions [72]. A $5 \% \mathrm{w} / \mathrm{v}$ sodium azide was added to the glucose-MIF solution to inhibit bacterial growth. A drop of toluene was added to the surface with a pasteur pipet to prevent sample evaporation. The solution was incubated at $37^{\circ} \mathrm{C}$. After 11 days, a mixture of $40 \%$ unmodified, $42 \%$ singly glycated, and $18 \%$ doubly glycated MIF was obtained.

\section{In solution pepsin digest}

To perform in-solution pepsin digest, $12 \mu \mathrm{L}$ of $10 \mathrm{mM}$ $\mathrm{HCl}, 2 \mu \mathrm{L}$ of $50 \mathrm{mM}$ TCEP in water, $1 \mu \mathrm{L}$ of acetonitrile, and $1 \mu \mathrm{L}$ of $0.2 \mathrm{~g} / \mathrm{L}$ porcine pepsin were added to $10 \mu \mathrm{L}$ recombinant MIF. Ten minutes after addition of pepsin solution (incubation at room temperature), $1 \mu \mathrm{L}$ of the digest was diluted $5 \times$ with alpha cyano 4 -hydroxy cinnaminic acid matrix solution (a saturated aqueous matrix solution with $33 \% \mathrm{v} / \mathrm{v}$ acetonitrile and $0.4 \% \mathrm{v} / \mathrm{v}$ trifluoroacetic acid) and all $5 \mu \mathrm{L}$ were spotted on the target. The matrixanalyte droplet was air-dried. Mass spectra were acquired on a Bruker Ultraflex operating in positive-ion reflectron mode, with ion source 1 at $25.00 \mathrm{kV}$, ion source 2 at $21.90 \mathrm{kV}$, lens at $9.50 \mathrm{kV}, 190 \mathrm{~ns}$ delay, and $2 \mathrm{GS} / \mathrm{s}$ sample rate. Approximately 1000 laser shots were acquired and summed for each mass spectrum. Prior to data acquisition, the target mass range was externally calibrated with a mixture of peptide calibrants obtained from Bruker Daltonics (Billerica, MA) consisting of bradykinin, angiotensin II, angiotensin I, Substance P, bombesin, ACTH (1-17), ACTH (18-39), and somatostatin. After data acquisition, the mass spectra were imported into MoverZ software. Peptides corresponding to $\mathrm{C}$-terminal cleavages at Phe, Leu, Tyr, and Trp, with up to 10 missed cleavages, were identified and the mass list was exported into PAWS software (Proteometrics, LLC).

\section{Abbreviations}

MIF: Macrophage migration inhibitory factor; MSIA: Mass spectrometric immunoassay; MALDI: Matrix-assisted laser desorption/ionization; TOF: Time-of-flight; CDI: Carbonyldiimidazole; HSA: Human serum albumin; PBS: Phosphate buffered saline; ACTH: Adrenocorticotropic hormone; TCEP: Tris(2-carboxyethyl)phosphine; DTPA: Diethylenetriaminepentaacetic acid; IRS: Internal reference standard; HisMIF: His tag MIF; ELISA: Enzyme-linked immunosorbent assay; RIA: Radioimmunoassay; EDTA: Ethylenediaminetetraacetic acid; CV: Coefficient of variation; PTM: Post translational modification.

\section{Competing interests}

The authors have declared no competing interests.

\section{Authors' contributions}

$N S, D N, C B, O T$, and JJ conceived and designed the experiments, with input from $\mathrm{PO}$ and RN. NS, OT, and JJ carried out the experiments. NS, DN, CB, OT, and DR performed data analysis. RN contributed analysis tools. NS wrote the manuscript. DN, CB, OT, JJ, and PO revised the manuscript. All authors read and approved the final manuscript. 


\section{Acknowledgments}

This project was supported by Award Numbers R01DK082542 and R24DK090958 from the National Institute of Diabetes and Digestive and Kidney Diseases. The content is solely the responsibility of the authors and does not necessarily represent the official views of the National Institute of Diabetes and Digestive and Kidney Diseases or the National Institutes of Health.

\section{Author details}

${ }^{1}$ The Biodesign Institute at Arizona State University, Tempe, AZ 85287, USA. ${ }^{2}$ Department of Chemistry \& Biochemistry at Arizona State University, Tempe, AZ 85287, USA.

Received: 7 July 2014 Accepted: 2 October 2014

Published online: 14 October 2014

\section{References}

1. Bloom BR, Bennett $B$ : Mechanism of a reaction in vitro associated with delayed-type hypersensitivity. Science 1966, 153(3731):80-82.

2. Weiser WY, Temple PA, Witek-Giannotti JS, Remold HG, Clark SC, David JR: Molecular cloning of a cDNA encoding a human macrophage migration inhibitory factor. Proc Natl Acad Sci U S A 1989, 86(19):7522-7526.

3. Leng L, Metz CN, Fang Y, Xu J, Donnelly S, Baugh J, Delohery T, Chen Y, Mitchell RA, Bucala R: MIF signal transduction initiated by binding to CD74. J Exp Med 2003, 197(11):1467-1476.

4. Shi X, Leng L, Wang T, Wang W, Du X, Li J, McDonald C, Chen Z, Murphy JW, Lolis E, Noble P, Knudson W, Bucala: CD44 is the signaling component of the macrophage migration inhibitory factor-CD74 receptor complex. Immunity 2006, 25(4):595-606.

5. Bernhagen J, Krohn R, Lue H, Gregory JL, Zernecke A, Koenen RR, Dewor M, Georgiev I, Schober A, Leng L, Kooistra T, Fingerle-Rowson G, Ghezzi P, Kleemann R, McColl SR, Bucala R, Hickey MJ, Weber C: MIF is a noncognate ligand of CXC chemokine receptors in inflammatory and atherogenic cell recruitment. Nat Med 2007, 13(5):587-596.

6. Kleemann R, Hausser A, Geiger G, Mischke R, Burger-Kentischer A, Flieger O, Johannes FJ, Roger T, Calandra T, Kapurniotu A, Grell M, Finkelmeier D, Brunner $\mathrm{H}$, Bernhagen J: Intracellular action of the cytokine MIF to modulate AP-1 activity and the cell cycle through Jab1. Nature 2000, 408(6809):211-216.

7. Calandra T, Roger T: Macrophage migration inhibitory factor: a regulator of innate immunity. Nat Rev Immunol 2003, 3(10):791-800.

8. Lue H, Kleemann R, Calandra T, Roger T, Bernhagen J: Macrophage migration inhibitory factor (MIF): mechanisms of action and role in disease. Microbes Infect 2002, 4(4):449-460

9. Nishino T, Bernhagen J, Shiiki H, Calandra T, Dohi K, Bucala R: Localization of macrophage migration inhibitory factor (MIF) to secretory granules within the corticotrophic and thyrotrophic cells of the pituitary gland. Mol Med 1995, 1(7):781-788.

10. Baugh JA, Donnelly SC: Macrophage migration inhibitory factor: a neuroendocrine modulator of chronic inflammation. J Endocrinol 2003, 179(1):15-23.

11. Rosengren E, Bucala R, Aman P, Jacobsson L, Odh G, Metz CN, Rorsman H: The immunoregulatory mediator macrophage migration inhibitory factor (MIF) catalyzes a tautomerization reaction. Mol Med 1996, 2(1):143-149.

12. Kleemann R, Kapurniotu A, Frank RW, Gessner A, Mischke R, Flieger O, Juttner $\mathrm{S}$, Brunner $\mathrm{H}$, Bernhagen J: Disulfide analysis reveals a role for macrophage migration inhibitory factor (MIF) as thiol-protein oxidoreductase. J Mol Biol 1998, 280(1):85-102.

13. Rosengren E, Aman P, Thelin S, Hansson C, Ahlfors S, Bjork P, Jacobsson L, Rorsman $\mathrm{H}$ : The macrophage migration inhibitory factor MIF is a phenylpyruvate tautomerase. FEBS Lett 1997, 417(1):85-88

14. Donnelly SC, Bucala R: Macrophage migration inhibitory factor: a regulator of glucocorticoid activity with a critical role in inflammatory disease. Mol Med Today 1997, 3(11):502-507.

15. Calandra T, Bernhagen J, Metz CN, Spiegel LA, Bacher M, Donnelly T, Cerami A, Bucala R: MIF as a glucocorticoid-induced modulator of cytokine production. Nature 1995, 377(6544):68-71.

16. Emonts M, Sweep FC, Grebenchtchikov N, Geurts-Moespot A, Knaup M, Chanson AL, Erard V, Renner P, Hermans PW, Hazelzet JA, Calandra T: Association between high levels of blood macrophage migration inhibitory factor, inappropriate adrenal response, and early death in patients with severe sepsis. Clin Infect Dis 2007, 44(10):1321-1328.

17. Lehmann LE, Novender U, Schroeder S, Pietsch T, von Spiegel T, Putensen C, Hoeft A, Stuber F: Plasma levels of macrophage migration inhibitory factor are elevated in patients with severe sepsis. Intensive Care Med 2001, 27(8):1412-1415.

18. Leech M, Metz C, Hall P, Hutchinson P, Gianis K, Smith M, Weedon H, Holdsworth SR, Bucala R, Morand EF: Macrophage migration inhibitory factor in rheumatoid arthritis: evidence of proinflammatory function and regulation by glucocorticoids. Arthritis Rheum 1999, 42(8):1601-1608.

19. Bozza FA, Gomes RN, Japiassu AM, Soares M, Castro-Faria-Neto HC, Bozza PT, Bozza MT: Macrophage migration inhibitory factor levels correlate with fatal outcome in sepsis. Shock 2004, 22(4):309-313.

20. de Mendonca-Filho HT, Gomes RV, de Almeida Campos LA, Tura B, Nunes EM, Gomes R, Bozza F, Bozza PT, Castro-Faria-Neto HC: Circulating levels of macrophage migration inhibitory factor are associated with mild pulmonary dysfunction after cardiopulmonary bypass. Shock 2004 22(6):533-537

21. Boekholdt SM, Peters RJ, Day NE, Luben R, Bingham SA, Wareham NJ, Hack CE, Reitsma PH, Khaw KT: Macrophage migration inhibitory factor and the risk of myocardial infarction or death due to coronary artery disease in adults without prior myocardial infarction or stroke: the EPIC-Norfolk Prospective Population study. Am J Med 2004, 117(6):390-397.

22. Burger-Kentischer A, Goebel H, Seiler R, Fraedrich G, Schaefer HE, Dimmeler $\mathrm{S}$, Kleemann R, Bernhagen J, Ihling C: Expression of macrophage migration inhibitory factor in different stages of human atherosclerosis. Circulation 2002, 105(13):1561-1566.

23. Chen Z, Sakuma M, Zago AC, Zhang X, Shi C, Leng L, Mizue Y, Bucala R, Simon D: Evidence for a role of macrophage migration inhibitory factor in vascular disease. Arterioscler Thromb Vasc Biol 2004, 24(4):709-714.

24. Garner LB, Willis MS, Carlson DL, DiMaio JM, White MD, White DJ, Adams GA IV, Horton JW, Giroir BP: Macrophage migration inhibitory factor is a cardiac-derived myocardial depressant factor. Am J Physiol Heart Circ Physiol 2003, 285(6):H2500-H2509.

25. Kleemann R, Bucala R: Macrophage migration inhibitory factor: critical role in obesity, insulin resistance, and associated comorbidities. Mediators Inflamm 2010, 2010:610479.

26. Kong YZ, Huang XR, Ouyang X, Tan JJ, Fingerle-Rowson G, Bacher M, Mu W, Scher LA, Leng L, Bucala R, Lan HY: Evidence for vascular macrophage migration inhibitory factor in destabilization of human atherosclerotic plaques. Cardiovasc Res 2005, 65(1):272-282.

27. Korshunov VA, Nikonenko TA, Tkachuk VA, Brooks A, Berk BC: Interleukin-18 and macrophage migration inhibitory factor are associated with increased carotid intima-media thickening. Arterioscler Thromb Vasc Biol 2006, 26(2):295-300.

28. Schober A, Bernhagen J, Thiele M, Zeiffer U, Knarren S, Roller M, Bucala R, Weber C: Stabilization of atherosclerotic plaques by blockade of macrophage migration inhibitory factor after vascular injury in apolipoprotein E-deficient mice. Circulation 2004, 109(3):380-385.

29. Miller EJ, Li J, Leng L, McDonald C, Atsumi T, Bucala R, Young LH: Macrophage migration inhibitory factor stimulates AMP-activated protein kinase in the ischaemic heart. Nature 2008, 451(7178):578-582.

30. Yu CM, Lau CP, Lai KW, Huang XR, Chen WH, Lan HY: Elevation of plasma level of macrophage migration inhibitory factor in patients with acute myocardial infarction. Am J Cardiol 2001, 88(7):774-777.

31. Bruchfeld A, Carrero JJ, Qureshi AR, Lindholm B, Barany P, Heimburger O, Hu M, Lin $X$, Stenvinkel $P$, Miller EJ: Elevated serum macrophage migration inhibitory factor (MIF) concentrations in chronic kidney disease (CKD) are associated with markers of oxidative stress and endothelial activation. Mol Med 2009, 15(3-4):70-75.

32. Herder C, Kolb H, Koenig W, Haastert B, Muller-Scholze S, Rathmann W, Holle R, Thorand B, Wichmann HE: Association of systemic concentrations of macrophage migration inhibitory factor with impaired glucose tolerance and type 2 diabetes: results from the Cooperative Health Research in the Region of Augsburg, Survey 4 (KORA S4). Diabetes Care 2006, 29 (2):368-371

33. Makino A, Nakamura T, Hirano M, Kitta $Y$, Sano K, Kobayashi T, Fujioka D, Saito Y, Watanabe K, Watanabe Y, Kawabata K, Obata JE, Kugiyama K: High plasma levels of macrophage migration inhibitory factor are associated with adverse long-term outcome in patients with stable coronary artery 
disease and impaired glucose tolerance or type 2 diabetes mellitus. Atherosclerosis 2010, 213(2):573-578.

34. Yabunaka N, Nishihira J, Mizue Y, Tsuji M, Kumagai M, Ohtsuka Y, Imamura M, Asaka M: Elevated serum content of macrophage migration inhibitory factor in patients with type 2 diabetes. Diabetes Care 2000, 23(2):256-258.

35. Hudson JD, Shoaibi MA, Maestro R, Carnero A, Hannon GJ, Beach DH: A proinflammatory cytokine inhibits p53 tumor suppressor activity. J Exp Med 1999, 190(10):1375-1382.

36. Xu X, Wang B, Ye C, Yao C, Lin Y, Huang X, Zhang Y, Wang S: Overexpression of macrophage migration inhibitory factor induces angiogenesis in human breast cancer. Cancer Lett 2008, 261(2):147-157.

37. Rendon BE, Roger T, Teneng I, Zhao M, Al-Abed Y, Calandra T, Mitchell RA: Regulation of human lung adenocarcinoma cell migration and invasion by macrophage migration inhibitory factor. J Biol Chem 2007, 282 (41):29910-29918

38. White ES, Strom SR, Wys NL, Arenberg DA: Non-small cell lung cancer cells induce monocytes to increase expression of angiogenic activity. $J$ Immunol 2001, 166(12):7549-7555.

39. Agarwal $R$, Whang $D H$, Alvero AB, Visintin I, Lai $Y$, Segal EA, Schwartz $P$, Ward D, Rutherford T, Mor G: Macrophage migration inhibitory factor expression in ovarian cancer. Am J Obstet Gynecol 2007, 196(4):348. e341-345.

40. He XX, Chen K, Yang J, Li XY, Gan HY, Liu CY, Coleman TR, Al-Abed Y: Macrophage migration inhibitory factor promotes colorectal cancer. Mol Med 2009, 15(1-2):1-10.

41. Meyer-Siegler K, Iczkowski K, Vera P: Further evidence for increased macrophage migration inhibitory factor expression in prostate cancer. BMC Cancer 2005, 5(1):73.

42. Prakash A, Rezai $T$, Krastins B, Sarracino D, Athanas M, Russo P, Zhang H, Tian Y, Li Y, Kulasingam V, Drabovich A, Smith CR, Batruch I, Oran PE, Fredolini C, Luchini A, Liotta L, Petricoin E, Diamandis EP, Chan DW, Nelson $R$, Lopez MF: Interlaboratory reproducibility of selective reaction monitoring assays using multiple upfront analyte enrichment strategies. J Proteome Res 2012, 11(8):3986-3995.

43. Rifai N, Gillette MA, Carr SA: Protein biomarker discovery and validation: the long and uncertain path to clinical utility. Nat Biotechnol 2006, 24(8):971-983.

44. Gillette MA, Carr SA: Quantitative analysis of peptides and proteins in biomedicine by targeted mass spectrometry. Nat Methods 2013, 10(1):28-34

45. Howard BA, Zheng Z, Campa MJ, Wang MZ, Sharma A, Haura E, Herndon JE 2nd, Fitzgerald MC, Bepler G, Patz EF Jr: Translating biomarkers into clinical practice: prognostic implications of cyclophilin A and macrophage migratory inhibitory factor identified from protein expression profiles in non-small cell lung cancer. Lung Cancer 2004, 46(3):313-323

46. Jensen $\mathrm{ON}$ : Modification-specific proteomics: characterization of posttranslational modifications by mass spectrometry. Curr Opin Chem Biol 2004, 8(1):33-41

47. Ong SE, Mann M: Mass spectrometry-based proteomics turns quantitative. Nat Chem Biol 2005, 1(5):252-262.

48. Cross JV, Rady JM, Foss FW, Lyons CE, Macdonald TL, Templeton DJ: Nutrient isothiocyanates covalently modify and inhibit the inflammatory cytokine macrophage migration inhibitory factor (MIF). Biochem J 2009, 423(3):315-321.

49. Watarai H, Nozawa R, Tokunaga A, Yuyama N, Tomas M, Hinohara A Ishizaka K, Ishii Y: Posttranslational modification of the glycosylation inhibiting factor (GIF) gene product generates bioactive GIF. Proc Natl Acad Sci U S A 2000, 97(24):13251-13256.

50. Nelson RW, Krone JR, Bieber AL, Williams P: Mass spectrometric immunoassay. Anal Chem 1995, 67(7):1153-1158.

51. Kiernan UA, Nedelkov D, Nelson RW: Multiplexed mass spectrometric immunoassay in biomarker research: a novel approach to the determination of a myocardial infarct. J Proteome Res 2006, 5(11):2928-2934

52. Kiernan UA, Addobbati R, Nedelkov D, Nelson RW: Quantitative multiplexed C-reactive protein mass spectrometric immunoassay. J Proteome Res 2006, 5(7):1682-1687.

53. Niederkofler EE, Kiernan UA, O'Rear J, Menon S, Saghir S, Protter AA, Nelson RW, Schellenberger U: Detection of endogenous B-type natriuretic peptide at very low concentrations in patients with heart failure. Circ Heart Fail 2008, 1(4):258-264.
54. Oran PE, Jarvis JW, Borges CR, Sherma ND, Nelson RW: Mass spectrometric immunoassay of intact insulin and related variants for population proteomics studies. Proteomics Clin App/ 2011, 5(7-8):454-459.

55. Oran PE, Sherma ND, Borges CR, Jarvis JW, Nelson RW: Intrapersonal and populational heterogeneity of the chemokine RANTES. Clin Chem 2010, 56(9):1432-1441.

56. Causon R: Validation of chromatographic methods in biomedical analysis. Viewpoint and discussion. J Chromatogr B Biomed Sci Appl 1997, 689(1):175-180.

57. DeSilva B, Smith W, Weiner R, Kelley M, Smolec J, Lee B, Khan M, Tacey R, Hill H, Celniker A: Recommendations for the bioanalytical method validation of ligand-binding assays to support pharmacokinetic assessments of macromolecules. Pharm Res 2003, 20(11):1885-1900.

58. Shah VP, Midha KK, Findlay JW, Hill HM, Hulse JD, McGilveray IJ, McKay G, Miller KJ, Patnaik RN, Powell ML, Tonelli A, Viswanathan CT, Yacobi: Bioanalytical method validation-a revisit with a decade of progress. Pharm Res 2000, 17(12):1551-1557.

59. Lee JW, Devanarayan V, Barrett YC, Weiner R, Allinson J, Fountain S, Keller S, Weinryb I, Green M, Duan L, Rogers JA, Millham R, O'Brien PJ, Sailstad J, Khan M, Ray C: Fit-for-purpose method development and validation for successful biomarker measurement. Pharm Res 2006, 23(2):312-328.

60. Bland JM, Altman DG: Measuring agreement in method comparison studies. Stat Methods Med Res 1999, 8(2):135-160.

61. Bland JM, Altman D: Statistical methods for assessing agreement between two methods of clinical measurement. Lancet 1986, 327(8476):307-310

62. Passing $H$, Bablok: A new biometrical procedure for testing the equality of measurements from two different analytical methods. Application of linear regression procedures for method comparison studies in clinical chemistry, Part I. J Clin Chem Clin Biochem 1983, 21(11):709-720.

63. Tuck MK, Chan DW, Chia D, Godwin AK, Grizzle WE, Krueger KE, Rom W, Sanda M, Sorbara L, Stass S, Wang W, Brenner DE: Standard operating procedures for serum and plasma collection: early detection research network consensus statement standard operating procedure integration working group. J Proteome Res 2009, 8(1):113-117.

64. Hsieh SY, Chen RK, Pan YH, Lee HL: Systematical evaluation of the effects of sample collection procedures on low-molecular-weight serum/plasma proteome profiling. Proteomics 2006, 6(10):3189-3198.

65. Zhang Q, Tang N, Brock JW, Mottaz HM, Ames JM, Baynes JW, Smith RD, Metz TO: Enrichment and analysis of nonenzymatically glycated peptides: boronate affinity chromatography coupled with electron-transfer dissociation mass spectrometry. J Proteome Res 2007, 6(6):2323-2330.

66. Barnaby OS, Cerny RL, Clarke W, Hage DS: Comparison of modification sites formed on human serum albumin at various stages of glycation. Clin Chim Acta 2011, 412(3-4):277-285.

67. Gerhardt W, Nordin G, Herbert AK, Burzell BL, Isaksson A, Gustavsson E, Haglund S, Muller-Bardorff M, Katus HA: Troponin T and I assays show decreased concentrations in heparin plasma compared with serum: lower recoveries in early than in late phases of myocardial injury. Clin Chem 2000, 46(6 Pt 1):817-821.

68. Evans MJ, Livesey JH, Ellis MJ, Yandle TG: Effect of anticoagulants and storage temperatures on stability of plasma and serum hormones. Clin Biochem 2001, 34(2):107-112.

69. Skogstrand K, Ekelund CK, Thorsen P, Vogel I, Jacobsson B, NorgaardPedersen B, Hougaard DM: Effects of blood sample handling procedures on measurable inflammatory markers in plasma, serum and dried blood spot samples. J Immunol Methods 2008, 336(1):78-84.

70. Burd EM: Validation of laboratory-developed molecular assays for infectious diseases. Clin Microbiol Rev 2010, 23(3):550-576.

71. Niederkofler EE, Tubbs KA, Kiernan UA, Nedelkov D, Nelson RW: Novel mass spectrometric immunoassays for the rapid structural characterization of plasma apolipoproteins. J Lipid Res 2003, 44(3):630-639.

72. Fu M-X, Wells-Knecht KJ, Blackledge JA, Lyons TJ, Thorpe SR, Baynes JW: Glycation, glycoxidation, and cross-linking of collagen by glucose: kinetics, mechanisms, and inhibition of late stages of the Maillard reaction. Diabetes 1994, 43(5):676-683.

doi:10.1186/s12953-014-0052-3

Cite this article as: Sherma et al:: Mass Spectrometric Immunoassay for the qualitative and quantitative analysis of the cytokine Macrophage Migration Inhibitory Factor (MIF). Proteome Science 2014 12:52. 